\title{
Morfofisiologia e valor nutritivo do capim-braquiária sob sombreamento natural e a sol pleno
}

\author{
Domingos Sávio Campos Paciullo(1), Carlos Augusto Brandão de Carvalho(2), Luiz Januário Magalhães Aroeira ${ }^{(1)}$, \\ Mirton José Frota Morenz ${ }^{(3)}$, Fernando César Ferraz Lopes $^{(1)}$ e Roberto Oscar Pereyra Rossiello(3)
}

\begin{abstract}
(1)Embrapa Gado de Leite, R. Eugênio do Nascimento, 610, Dom Bosco, CEP 36038-330 Juiz de Fora, MG. E-mail: domingos@cnpgl.embrapa.br, laroeira@cnpgl.embrapa.br, fernando@cnpgl.embrapa.br ${ }^{(2)}$ Agência Paulista de Tecnologia dos Agronegócios, Pólo Regional do Vale do Paraíba, Av. Prof. Manoel César Ribeiro, 320, CEP 12400-970 Pindamonhangaba, SP. E-mail: cabcarva@aptaregional.sp.gov.br (3)Universidade Federal Rural do Rio de Janeiro, BR 465, Km 7, CEP 23890-000 Seropédica, RJ. E-mail: morenz@yahoo.com.br, ropr@ufrri.br
\end{abstract}

\begin{abstract}
Resumo - O objetivo deste trabalho foi avaliar características morfofisiológicas e o valor nutritivo da Brachiaria decumbens, nas épocas chuvosas de 2003 e 2004, em um sistema silvipastoril, com faixas de $30 \mathrm{~m}$ de largura com essa gramínea, alternadas com faixas de $10 \mathrm{~m}$ com árvores de Acacia mangium, A. angustissima, Mimosa artemisiana, Leucaena leucocephala x L. diversifolia, Eucalyptus grandis. Foi adotado o delineamento de blocos ao acaso, em parcelas subsubdivididas (características morfofisiológicas) ou parcelas subdivididas (características do valor nutritivo), com quatro repetições. Em 2003, o sombreamento foi de $65 \%$ da radiação incidente fora do bosque e, em 2004, de 35\%, depois da retirada de árvores de eucalipto. Sob sombreamento, a densidade de perfilhos, o índice de área foliar e a massa de forragem foram maiores no segundo ano. Os teores médios de fibra em detergente neutro (FDN) foram maiores a pleno sol que sob sombreamento, enquanto os valores médios de proteína bruta $(\mathrm{PB})$ e a digestibilidade in vitro da matéria seca foram maiores à sombra. $\mathrm{O}$ sombreamento moderado aumenta os teores de PB, reduz os teores de FDN e incrementa a digestibilidade da forragem de gramíneas que crescem sob a copa das árvores.
\end{abstract}

Termos para indexação: Brachiaria decumbens, digestibilidade, índice de área foliar, leguminosa arbórea, sistema silvipastoril.

\section{Morphophysiology and nutritive value of signalgrass under natural shading and full sunlight}

\begin{abstract}
The objective of this trial was to evaluate the morphophysiological traits and nutritive value of Brachiaria decumbens, during 2003 and 2004 rainy seasons, in a silvopastoral system, with grass alone $(30 \mathrm{~m}$ width), alternated with grass plus trees (Acacia mangium, A. angustissima, Mimosa arthemisiana, Leucaena leucocephala $\mathrm{x}$ L. diversifolia, Eucalyptus grandis) strips (10 m width). The experimental design was a randomized block arranged in a split plot design (morphophysiological traits) or split-split plot (nutritive value traits), and replicated four times. The level of shading was 65\% of incident radiation out of the wood in 2003, and 35\% in 2004 after harvesting of some Eucalyptus trees. Under shade, tiller population leaf area and forage mass index were higher in the second year than in the first. Forage neutral detergent fiber value was higher at full sunlight than in the shade, while the crude protein content and in vitro dry matter digestibility were higher under the trees. Moderate shading increases crude protein and reduces neutral detergent fiber, therefore improving forage digestibility of grasses growing under trees.

Index terms: Brachiaria decumbens, digestibility, leaf area index, tree legume, silvopastoral system.
\end{abstract}

\section{Introdução}

Os sistemas de produção de bovinos no Brasil são, em sua maioria, baseados na utilização de pastagens. Estimativas admitem que 80 a $90 \%$ das áreas de pastagens no País são constituídas por espécies forrageiras, do gênero Brachiaria, principalmente $B$. decumbens e $B$. brizantha (Boddey et al., 2004). Grande parte das pastagens de braquiária, cultivada em diferentes regiões do Brasil, tem mostrado sinais de degradação após poucos anos de uso, por causa do excesso de pastejo e da queda da fertilidade dos solos, especialmente por deficiência de nitrogênio (Boddey et al., 2004; Macedo, 2005).

O uso de sistemas silvipastoris pode ser uma alternativa viável para recuperar e desenvolver novas pastagens de gramíneas, em regiões de pecuária de leite, de forma sustentável. Entre os benefícios para os componentes do sistema solo/planta/animal, destacam-se a conservação do solo e da água, a possibilidade de 
melhoria das condições físicas, químicas e da atividade biológica na superfície do solo, e o conforto térmico para os animais (Jackson \& Ash, 1998; Wilson, 1998; Leme et al., 2005).

O enriquecimento do solo de pastagens, em áreas sob a influência das copas de árvores, tem sido observado em várias regiões e ocorre em razão do aproveitamento de nutrientes pelas árvores, de camadas do solo que estão fora do alcance das raízes das forrageiras, e à incorporação gradativa de biomassa das árvores (folhas, flores, frutos etc) à pastagem (Sánchez et al., 2003). A velocidade do processo de decomposição da serrapilheira torna-se mais eficiente, quando há presença de leguminosas arbóreas, cuja baixa relação carbono/ nitrogênio favorece a atividade dos microrganismos e acelera os processos de decomposição e mineralização dos principais nutrientes do ecossistema (Wilson, 1996).

Sabe-se que as árvores reduzem a luminosidade disponível para as forrageiras que crescem sob suas copas, condição que influencia o valor nutritivo da forragem e os aspectos morfogenéticos determinantes da produtividade (Deinum et al., 1996; Carvalho et al., 1997; Castro et al., 1999). Embora ainda escassos, os estudos sobre os aspectos morfofisiológicos e nutricionais da interação entre árvores e gramíneas forrageiras mostram que os efeitos dependem tanto da espécie forrageira considerada, quanto do nível de sombreamento imposto pelas espécies arbóreas associadas.

Em geral, a taxa de crescimento e a produção de forragem decrescem com o aumento das condições de sombreamento, embora, dependendo da espécie, maiores rendimentos forrageiros podem ser obtidos, em condições de sombra moderada (Carvalho, 2001). Castro et al. (1999) observaram que a espécie Brachiaria decumbens, cultivada em condições de sombreamento artificial moderado $(30 \%$ em relação à radiação fotossinteticamente ativa plena), produziu $70 \%$ da quantidade de forragem obtida a pleno sol. No mesmo estudo, os autores concluíram que as espécies Panicum maximum e Setaria sphacelata foram as mais tolerantes ao sombreamento e atingiram, respectivamente, à sombra moderada, 119,7 e 100,5\% da produção de matéria seca obtida a pleno sol. Andrade et al. (2004) constataram decréscimo acentuado na taxa de crescimento da B. brizantha, quando as plantas foram submetidas ao sombreamento intenso (mais de $50 \%$ de redução da luminosidade).

$\mathrm{O}$ aumento da disponibilidade de vários nutrientes no solo, sob sombreamento, pode resultar em melhoria dos teores de proteína bruta e de minerais na forragem, tais como cálcio, fósforo e potássio (Deinum et al., 1996; Durr \& Rangel, 2000), em comparação com pleno sol. Sobre os teores de fibra e a digestibilidade, os resultados são contraditórios, embora alguns indiquem tendência de redução dos teores de fibra em detergente neutro e aumento da digestibilidade in vitro da matéria seca, em condições de sombra (Carvalho, 2001).

O objetivo deste trabalho foi avaliar algumas características morfofisiológicas e o valor nutritivo de B. decumbens, cultivada em condições de sombreamento por árvores e a sol pleno.

\section{Material e métodos}

O experimento foi realizado na Embrapa Gado de Leite, em Coronel Pacheco, MG, em um sistema silvipastoril instalado em área de topografia montanhosa, com declividade de aproximadamente $30 \%$. O solo da área é classificado como Latossolo Vermelho-Amarelo, de baixa fertilidade natural. A precipitação média mensal é de $60 \mathrm{~mm}$, e a temperatura média é de $17^{\circ} \mathrm{C}$, de abril a setembro, e de $230 \mathrm{~mm}$ e $24^{\circ} \mathrm{C}$, de outubro a março. As coordenadas geográficas do local são $21^{\circ} 33^{\prime} 22^{\prime \prime S}$ e $43^{\circ} 6^{\prime} 15^{\prime \prime} \mathrm{W}$, a altitude é de $410 \mathrm{~m}$. O clima da região, de acordo com a classificação de Köppen, é do tipo Cwa (mesotérmico).

O sistema silvipastoril foi implantado em novembro de 1997, com a gramínea B. decumbens cv. Basilisk estabelecida em faixas de $30 \mathrm{~m}$ de largura, alternadas em faixas de $10 \mathrm{~m}$, estabelecidas em nível, constituídas de quatro linhas com as leguminosas arbóreas Acacia mangium, A. angustissima, Mimosa artemisiana e a arbustiva Leucaena leucocephala x L. diversifolia, além do Eucalyptus grandis. Dentro das faixas, as árvores foram plantadas em um espaçamento de $3 \times 3 \mathrm{~m}$, seguindo, nas linhas, a distribuição de uma espécie após a outra, de forma que cada árvore da mesma espécie ficou distanciada da outra em $15 \mathrm{~m}$. Antes do plantio, em novembro de 1997, aplicaram-se nas faixas de $30 \mathrm{~m}$, que seria introduzidas com a braquiária, $1.000 \mathrm{~kg} \mathrm{ha}^{-1}$ de calcário dolomítico, $600 \mathrm{~kg} \mathrm{ha}^{-1}$ de fosfato de Araxá, $25 \mathrm{~kg} \mathrm{ha}^{-1}$ de superfosfato simples, $100 \mathrm{~kg} \mathrm{ha}^{-1}$ de cloreto de potássio e $30 \mathrm{~kg} \mathrm{ha}^{-1}$ de FTE BR-16.

Entre 1998 e 2000, o sistema silvipastoril permaneceu vedado, a fim de se garantir o crescimento inicial das espécies arbóreas. A área foi dividida em seis piquetes de 0,5 ha e, em 2001 e 2002, foi utilizada para o pastejo 
de vacas não lactantes, tendo-se respeitado períodos de ocupação e descanso de cinco e 45 dias, respectivamente.

A partir de janeiro de 2003, iniciou-se o pastejo por novilhas, em regime de lotação rotativa, com período de ocupação de sete dias e de descanso de 35 dias. As avaliações foram realizadas no período das chuvas, durante dois anos (2003 e 2004).

Foram estudados dois ambientes, em termos de irradiância solar recebida: radiação solar plena (faixa sem árvores, distante $15 \mathrm{~m}$ do componente arbóreo) e sob sombreamento natural de árvores (faixa com árvores). De janeiro a setembro de 2003, a pastagem apresentava densidade aproximada de 170 árvores por hectare; considerou-se a área total do sistema silvipastoril as faixas arborizadas e não-arborizadas. Dentro das faixas arborizadas, a densidade nesse período foi de 510 árvores por hectare. Em outubro/novembro de 2003, de acordo com a previsão inicial do sistema, de realizar o desbaste de parte das árvores de eucalipto aos seis anos, 30\% das árvores de E. Grandis foram cortadas, o que resultou em diminuição da densidade para 110 árvores por hectare, na área total, e 330 árvores por hectare apenas nas faixas com árvores. Por meio de medições da radiação solar, recebida no topo do relvado de B. decumbens, em condições de pleno sol e de sombreamento, constatou-se que o sub-bosque de braquiária considerando-se todas as faixas com árvores, recebeu, em média, $35 \%$ da radiação incidente a pleno sol (65\% de sombreamento), durante o primeiro ano, e $65 \%$ (35\% de sombreamento), durante o segundo ano. O desbaste de $30 \%$ das árvores de eucalipto proporcionou aumento de luminosidade de $85 \%$ no subbosque, o que é explicado pela maior contribuição dessa espécie com o sombreamento do pasto, em razão do seu crescimento mais rápido que o das demais espécies.

Cada piquete foi estratificado em oito áreas de mesmo tamanho; quatro na faixa sem árvores e quatro na faixa com árvores. Ao final do período de descanso do piquete, foram coletadas, em cada parcela de $625 \mathrm{~m}^{2}$, quatro amostras com auxílio de uma moldura de $0,5 \mathrm{x}$ 0,5 m, para avaliação da massa de forragem, densidade populacional de perfilhos, área foliar específica (AFE) e índice de área foliar (IAF). Foram realizadas cinco amostragens, iniciadas em novembro de cada ano, estendidas até abril do ano seguinte, sempre a cada 35 dias, de acordo com o intervalo de pastejo. A forragem foi cortada no nível do solo e separada em materiais verde e morto; na parte verde foi contado o número de perfilhos. Posteriormente, os perfilhos foram separados em lâmina foliar e colmo mais bainha foliar. Depois da pesagem de cada componente, foi retirada uma subamostra, para secagem em estufa regulada para $55^{\circ} \mathrm{C}$. Outra subamostra serviu para avaliação das áreas foliares (medidor de área LICOR, modelo LI 3000), a fim de se obter o IAF e a AFE.

Medidas da interceptação da radiação fotossinteticamente ativa (RFA), pelo dossel de $B$. decumbens, foram realizadas apenas no primeiro ano de avaliação, com utilização de um sensor de RFA (modelo LI-190SA) conectado a um radiômetro portátil (LICOR, modelo LI-189). Tais valores foram obtidos em 15 pontos, por meio de leituras, da irradiância fotossintética, incidente no topo do dossel e no nível da superfície do solo. Com base nessas leituras foram calculadas as diferenças entre as RFA acima e abaixo do dossel, em porcentagem. Essas medições foram feitas previamente ao corte da gramínea.

As amostras de folha e colmo, obtidas ao final de cada período de descanso, foram agrupadas em amostras compostas que representaram o período experimental de cada ano. Em seguida, foram moídas e analisadas quanto à digestibilidade in vitro da matéria seca (DIVMS) e aos teores de matéria seca (MS), proteína bruta (PB), fibra em detergente neutro (FDN), fibra em detergente ácido (FDA) e lignina, confome Silva \& Queiroz (2002).

Para as variáveis massa de forragem, IAF, AFE e densidade de perfilhos, foi adotado o delineamento experimental de blocos completos ao acaso, com arranjo em subparcelas, com quatro repetições. Nas parcelas, foram avaliados, no mesmo piquete, os efeitos dos dois ambientes, em termos de irradiância solar recebida (radiação solar plena e sob sombreamento natural de árvores). Nas subparcelas, foram observados os efeitos dos anos de avaliação. Para a variável interceptação luminosa, foi usado o delineamento de blocos ao acaso, e foram testados apenas os efeitos dos dois ambientes de irradiância solar, uma vez que essa variável foi estudada apenas no primeiro ano. Para as variáveis de valor nutritivo, foi usado o delineamento de blocos e o esquema de parcelas subsubdividas, os ambientes de luminosidade estudados nas parcelas, as frações (colmo e folha) nas subparcelas e os anos de avaliação, nas subsubparcelas.

Os resultados foram submetidos à análise de variância, com utilização do programa SISVAR v. 4.3, e as médias foram comparadas pelo teste $\mathrm{F}$, a $5 \%$ de probabilidade. 


\section{Resultados e Discussão}

A Tabela 1 apresenta o desdobramento da interação entre as condições de luminosidade (ou níveis de sombreamento) e os anos de avaliação, significativa $(\mathrm{p}<0,05)$ para as variáveis massa de forragem, IAF e densidade populacional de perfilhos. Para a condição de sol pleno, os valores não variaram $(\mathrm{p}>0,05) \mathrm{em}$ decorrência do ano de avaliação. Entretanto, sob sombreamento, as médias foram maiores no segundo ano, em relação ao primeiro, o que refletiu, principalmente, a maior irradiância solar recebida pelo relvado de braquiária em 2004.

Um componente importante da produção de forragem, fortemente influenciado pelas condições de luminosidade, foi a densidade de perfilhos. $\mathrm{O}$ sombreamento natural, proporcionado por árvores, alterou tanto a intensidade quanto a qualidade (relação vermelho:vermelho distante) da radiação incidente no sub-bosque. A redução da relação vermelho:vermelho distante, em condições de sombreamento natural, apresentou importantes efeitos sobre a morfogênese das plantas, principalmente por diminuir o perfilhamento das gramíneas (Gautier et al., 1999), o que explica a menor densidade de perfilhos observada nas condições de sombra, especialmente no primeiro ano.

A baixa densidade de perfilhos, em condições de sombreamento intenso (65\%), ajuda a explicar a redução

Tabela 1. Matéria seca de forragem verde (MSFV), índice de área foliar (IAF), densidade populacional de perfilhos (DPP) e interceptação da radiação fotossinteticamente ativa (RFA), em relvado de Brachiaria decumbens, de acordo com a condição de luminosidade e o ano de avaliação. Valores médios obtidos na condição de pré-pastejo ${ }^{(1)}$.

\begin{tabular}{|c|c|c|}
\hline \multirow[t]{2}{*}{ Ano de avaliação ${ }^{(2)}$} & \multicolumn{2}{|c|}{ Condição de luminosidade } \\
\hline & Sol pleno & Sombreamento por árvores \\
\hline & \multicolumn{2}{|c|}{$\operatorname{MSFV}\left(\mathrm{kg} \mathrm{ha}^{-1}\right)$} \\
\hline 2003 & $1.501 \mathrm{aA}$ & $698 \mathrm{bB}$ \\
\hline 2004 & $1.260 \mathrm{aA}$ & $1.158 \mathrm{aA}$ \\
\hline & \multicolumn{2}{|r|}{ IAF } \\
\hline 2003 & $1,52 \mathrm{aA}$ & $0,72 \mathrm{bB}$ \\
\hline 2004 & $1,75 \mathrm{aA}$ & $1,62 \mathrm{aA}$ \\
\hline & \multicolumn{2}{|c|}{ DPP (perfilhos $\mathrm{m}^{-2}$ ) } \\
\hline 2003 & $534 \mathrm{aA}$ & $253 \mathrm{bB}$ \\
\hline 2004 & $517 \mathrm{aA}$ & $447 \mathrm{aA}$ \\
\hline & \multicolumn{2}{|c|}{ Interceptação da RFA (\%) } \\
\hline 2003 & $74,2 \mathrm{a}$ & $70,0 \mathrm{a}$ \\
\hline 2004 & n.a. ${ }^{(3)}$ & n.a. \\
\hline
\end{tabular}

(1)Médias seguidas por letras iguais, minúsculas na linha e maiúsculas nas colunas, não diferem entre si pelo teste $\mathrm{F}$, a $5 \%$ de probabilidade. (2) 2003: 65\% de sombreamento; 2004: 35\% de sombreamento. ${ }^{(3)} \mathrm{Não}$ avaliado. acentuada da massa de forragem da $B$. decumbens, em condições de luminosidade reduzida.

De fato, na maioria dos estudos com gramíneas tropicais, existem relatos sobre a redução na produção de forragem sob sombreamento intenso, em razão da acentuada diminuição das taxas fotossintéticas das gramíneas de ciclo C4 (Deinum et al., 1996; Castro et al., 1999; Andrade et al., 2004). Castro et al. (1999) mostraram redução de $50 \%$ no rendimento forrageiro dessa espécie, quando cultivada com $60 \%$ de sombreamento artificial. A espécie Brachiaria brizantha cv. Marandu também apresentou diminuição de $60 \%$ na taxa de acúmulo de MS, quando cultivada sob sombreamento artificial de $70 \%$ (Andrade et al., 2004).

Entretanto, a retirada de árvores de E. grandis, no final de 2003, favoreceu a penetração de luz através da copa das árvores, o que proporcionou aumentos de 65, 125 e $95 \%$ para a massa de forragem, IAF e densidade de perfilhos. Assim, constatou-se que com $35 \%$ de sombreamento, desapareceram as diferenças da braquiária no bosque de árvores e a pleno sol. Tal fato evidenciou a tolerância da B. decumbens ao sombreamento moderado (35\%), conforme resultados de Shelton et al. (1987), que consideraram essa espécie medianamente tolerante ao sombreamento.

A interceptação da RFA não variou ( $p>0,05)$ com as condições de sombreamento; apresentou valores médios de 74,2 e $70 \%$ em sol pleno e sombreamento, respectivamente (Tabela 1). No momento da amostragem, os valores médios de IAF estimados foram 1,52 e 0,72, respectivamente, à luz solar plena e em condições de sombreamento. Nota-se que, com praticamente metade do IAF, o pasto de B. decumbens, sob a copa das árvores, foi capaz de interceptar a mesma proporção da RFA que as plantas que se desenvolveram sob condições de luz solar plena. A interceptação luminosa não depende somente dos valores de IAF, mas também de fatores como ângulo foliar, disposição das folhas no dossel, entre outros (Haynes, 1980). A baixa luminosidade promoveu alterações morfológicas no dossel de $B$. decumbens que permitiram aumentar a interceptação com baixo valor de IAF. Por observações visuais, constatou-se que as plantas que se desenvolveram sob as copas das árvores apresentavam arquitetura foliar mais horizontal (planófila), em relação àquelas desenvolvidas sob radiação solar plena, o que pode ter provocado aumento no grau de atenuação da luz ao atravessar o dossel. Deve-se considerar, também, que a maior proporção de radiação difusa na pastagem 
arborizada, provavelmente, contribuiu para maior interceptação da radiação pela braquiária.

Uma das respostas ao sombreamento foi o aumento da AFE, cujos valores variaram $(\mathrm{p}<0,01)$ com a condição de luminosidade (Tabela 2). Independentemente do ano de avaliação, observaram-se maiores valores para as plantas sob sombreamento, em relação às cultivadas sob radiação solar plena. $\mathrm{O}$ ano de avaliação não influenciou ( $>0,05)$ os valores de AFE, isto é evidência de que uma pequena redução da luminosidade, como observado no segundo ano experimental (35\% de sombreamento), foi suficiente para promover aumentos da AFE, em consequiência da formação de folhas maiores e mais delgadas (Castro et al., 1999). Esses resultados são evidências de que o dossel de $B$. decumbens aumenta a eficiência de utilização da radiação disponível em condições de sombreamento.

Nenhuma das variáveis do valor nutritivo foi influenciada $(p>0,05)$ pelo ano experimental ou pelas suas interações com as demais variáveis. Os teores de PB foram influenciados pela interação condição de luminosidade x fração da planta (Tabela 3). No colmo, não foi observada variação do teor de PB com a condição de luz, mas, na folha, o valor médio foi $29 \%$ maior na sombra que a pleno sol. O efeito positivo do sombreamento nos teores de PB está bem estabelecido na literatura, especialmente em solos com baixos teores de nitrogênio (Deinum et al., 1996; Wilson, 1998).

Tabela 2. Área foliar específica $\left(\mathrm{cm}^{2} \mathrm{~g}^{-1}\right)$, em relvado de Brachiaria decumbens, de acordo com a condição de luminosidade e $\mathrm{o}$ ano de avaliação. Valores médios obtidos na condição de pré-pastejo ${ }^{(1)}$.

\begin{tabular}{cccc}
\hline Ano de avaliação $^{(2)}$ & \multicolumn{2}{c}{ Condição de luminosidade } & \multirow{2}{*}{ Média } \\
\cline { 2 - 3 } & Sol pleno & Sombreamento por árvores & \\
\hline 2003 & 142,3 & 179,2 & $160,8 \mathrm{~A}$ \\
2004 & 134,7 & 163,5 & $149,1 \mathrm{~A}$ \\
\hline Média & $138,8 \mathrm{~b}$ & $171,4 \mathrm{a}$ & 155,1 \\
\hline
\end{tabular}

(1)Médias seguidas por letras iguais, minúsculas na linha e maiúsculas nas colunas, não diferem entre si pelo teste $\mathrm{F}$, a $5 \%$ de probabilidade.

(2) 2003: $65 \%$ de sombreamento; 2004: $35 \%$ de sombreamento.

Tabela 3. Teores de proteína bruta da Brachiaria decumbens, de acordo com as condições de luminosidade e a fração da planta $^{(1)}$.

\begin{tabular}{lcc}
\hline Fração da planta & \multicolumn{2}{c}{ Condições de luminosidade } \\
\cline { 2 - 3 } & Sol pleno & Sombreamento por árvores \\
\hline Folha & $9,6 \mathrm{bA}$ & $12,4 \mathrm{aA}$ \\
Colmo & $4,6 \mathrm{aB}$ & $4,7 \mathrm{aB}$ \\
\hline
\end{tabular}

${ }^{(1)}$ Médias seguidas por letras iguais, minúsculas na linha e maiúsculas nas colunas, não diferem entre si pelo teste $\mathrm{F}$, a $5 \%$ de probabilidade.
Em condições de sombreamento natural, observam-se aumentos da degradação da matéria orgânica e da reciclagem de nitrogênio no solo (Wilson, 1996). Assim, boa parte do benefício da sombra, nos teores de PB, está associada à melhoria da fertilidade do solo (Durr \& Rangel, 2000; Xavier et al., 2003), especialmente quando as árvores presentes na pastagem são leguminosas fixadoras de nitrogênio atmosférico.

Os teores de FDN, FDA e lignina foram maiores $(\mathrm{p}<0,05)$ no colmo que nas folhas, enquanto a DIVMS da folha foi maior $(\mathrm{p}<0,05)$ que a do colmo (Tabela 4). Esses resultados estão de acordo com a literatura, em que, para diferentes espécies de forrageiras, observouse o melhor valor nutritivo das lâminas foliares em comparação ao do colmo (Queiroz et al., 2000; Paciullo et al., 2001).

A condição de luminosidade não influenciou nos teores de FDA e lignina; mas foi observado efeito $(p<0,05)$ isolado do ambiente luminoso nos teores de FDN, cujos valores foram menores sob a copa das árvores que em condições de luz solar plena (Tabela 5). Resultados semelhantes foram constatados por Deinum et al. (1996)

Tabela 4. Teores de fibra em detergente neutro (FDN), fibra em detergente ácido (FDA), lignina e digestibilidade in vitro da matéria seca (DIVMS) da Brachiaria decumbens, de acordo com a fração da planta. Valores médios obtidos nas condições de sombreamento e sol pleno, nos dois anos experimentais $^{(1)}$.

\begin{tabular}{lcc}
\hline Característica & \multicolumn{2}{c}{ Fração da planta } \\
\cline { 2 - 3 } & $67,4 \mathrm{~b}$ & Colmo \\
\hline FDN & $31,5 \mathrm{~b}$ & $81,7 \mathrm{a}$ \\
FDA & $5,4 \mathrm{~b}$ & $43,1 \mathrm{a}$ \\
Lignina & $58,0 \mathrm{a}$ & $9,0 \mathrm{a}$ \\
DIVMS & $42,9 \mathrm{~b}$ \\
\hline${ }^{(1)}$ Médias seguidas por letras iguais, nas linhas, não diferem entre si pelo \\
teste F, a 5\% de probabilidade.
\end{tabular}

Tabela 5. Teores de fibra em detergente neutro (FDN), fibra em detergente ácido (FDA), lignina e digestibilidade in vitro da matéria seca (DIVMS) da Brachiaria decumbens, de acordo com as condições de luminosidade. Valores médios obtidos para as frações colmo e lâmina foliar, nos dois anos experimentais $^{(1)}$.

\begin{tabular}{lcc}
\hline Característica & \multicolumn{2}{c}{ Condições de luminosidade } \\
\cline { 2 - 3 } & Sol pleno & Sombreamento por árvores \\
\hline FDN & $75,9 \mathrm{a}$ & $73,1 \mathrm{~b}$ \\
FDA & $36,4 \mathrm{a}$ & $38,0 \mathrm{a}$ \\
Lignina & $7,3 \mathrm{a}$ & $7,2 \mathrm{a}$ \\
DIVMS & $47,6 \mathrm{~b}$ & $53,2 \mathrm{a}$ \\
\hline (1) Médias seguidas por letras iguais, nas linhas, não diferem entre si pelo & \\
teste F, a 5\% de probabilidade.
\end{tabular}


com Brachiaria brizantha e Panicum maximum, cultivadas sob diferentes graus de sombreamento artificial. De acordo com esses autores, os maiores teores de FDN, em condições de alta luminosidade, podem ser associados à maior proporção de tecido esclerenquimático, cujas células apresentam paredes mais espessas do que em condições de sombreamento.

Os coeficientes de DIVMS foram maiores $(\mathrm{p}<0,05)$ na sombra que a sol pleno (Tabela 5). A maior DIVMS da B. decumbens esteve relacionada ao maior teor de $\mathrm{PB}$ foliar e menor de FDN, em condições de sombreamento. Deinum et al. (1996) observaram, sob condições idênticas de cultivo, ausência de efeitos para $B$. brizantha e efeitos negativos para Panicum maximum, o que indica inconsistência do efeito da sombra na digestibilidade, pois esse pode variar com a espécie forrageira, o grau de sombreamento e a estação do ano. Senanayake (1995) relatou que a DIVMS de quatro gramíneas forrageiras foi reduzida sob sombreamento intenso (28\% de transmissão de luz); mas aumentou sob sombra moderada (64\% de transmissão de luz), quando comparada à condição de luz solar plena. Para B. decumbens, o sombreamento não influenciou os valores de DIVMS, durante a época das chuvas, mas aumentou acentuadamente durante a seca, em razão de as melhores condições de umidade de solo, sob as copas das árvores, terem permitido que as plantas permanecessem verdes durante essa época do ano (Carvalho et al., 1994).

A semelhança nas características morfológicas e na massa de forragem do pasto de B. decumbens, em condições de sombreamento moderado (ano de 2004) e radiação solar plena, e os maiores valores de PB e DIVMS sob a copa das árvores, são evidências de algumas vantagens do estabelecimento de pastagens arborizadas, especialmente aquelas com leguminosas arbóreas, como principal componente florestal. Além disto, deve-se considerar que o processo de fixação de nitrogênio pelas leguminosas arbóreas, em solos normalmente pobres nesse elemento, como os tropicais, possibilita redução do uso de fertilizantes nitrogenados.

\section{Conclusões}

1. O sombreamento intenso ( $65 \%$ de sombra) reduz os valores de massa de forragem, densidade de perfilhos e índice de área foliar da Brachiaria decumbens, enquanto o sombreamento moderado ( $35 \%$ de sombra) não modifica essas variáveis, em relação ao cultivo a sol pleno.

2. O sombreamento provoca alterações morfológicas no relvado de $B$. decumbens, que contribuem para o aumento da interceptação da radiação fotossinteticamente ativa.

3. O sombreamento provocado pela presença das árvores, no sistema silvipastoril, possibilita aumento dos teores de proteína bruta e redução dos de fibra em detergente neutro, e incrementa a digestibilidade in vitro da matéria seca da $B$. decumbens, cultivada no subbosque.

\section{Referências}

ANDRADE, C.M.S. de; VALENTIM, J.F.; CARNEIRO, J. da C.; VAZ, F.A. Crescimento de gramíneas e leguminosas forrageiras tropicais sob sombreamento. Pesquisa Agropecuária Brasileira, v.39, p.263-270, 2004.

BODDEY, R.M.; MACEDO, R.; TARRÉ, R.M.; FERREIRA, E.; OLIVEIRA, O.C. de; REZENDE, C. de P.; CANTARUTTI, R.B.; PEREIRA, J.M.; ALVES, B.J.R.; URQUIAGA, S. Nitrogen cycling in Brachiaria pastures: the key to understanding the process of pasture decline. Agriculture, Ecosystems and Environment, v.103, p.389-403, 2004.

CARVALHO, M.M. Contribuição dos sistemas silvipastoris para a sustentabilidade da atividade leiteira. In: SIMPÓSIO SOBRE SUSTENTABILIDADE DE SISTEMAS DE PRODUÇÃO DE LEITE A PASTO E EM CONFINAMENTO, 2001, Juiz de Fora. Anais. Juiz de Fora: Embrapa Gado de Leite, 2001. p.85-108.

CARVALHO, M.M.; FREITAS, V.P.; ALMEIDA, D.S.; VILLAÇA, H.A. Efeito de árvores isoladas sobre a disponibilidade e composição mineral da forragem de pastagens de braquiária. Revista da Sociedade Brasileira de Zootecnia, v.23, p.709-718, 1994.

CARVALHO, M.M.; SILVA, J.L.O.; CAMPOS JÚNIOR, B.A. Produção de matéria seca e composição mineral da forragem de seis gramíneas tropicais estabelecidas em um sub-bosque de angicovermelho. Revista Brasileira de Zootecnia, v.26, p.213-218, 1997.

CASTRO, C.R.T. de; GARCIA, R.; CARVALHO, M.M.; COUTO, L. Produção forrageira de gramíneas cultivadas sob luminosidade reduzida. Revista Brasileira de Zootecnia, v.28, p.919-927, 1999.

DEINUM, B.; SULASTRI, R.D.; ZEINAB, M.H.J.; MAASSEN, A. Effects of light intensity on growth, anatomy and forage quality of two tropical grasses (Brachiaria brizantha and Panicum maximum var. Trichoglume). Netherlands Journal of Agricultural Science, v.44, p.111-124, 1996.

DURR, P.A.; RANGEL, J. The response of Panicum maximum to a simulated subcanopy environment. I. Soil x shade interaction. Tropical Grasslands, v.34, p.110-117, 2000.

GAUTIER, H.; VARLET-GRANCHER, C.; HAZARD, L. Tillering responses to the light environment and to defoliation in populations of perennial ryegrass (Lolium perenne L.) selected for contrasting leaf length. Annals of Botany, v.83, p.423-429, 1999. 
HAYNES, R.J. Competitive aspects of the grass-legume association. Advances in Agronomy, v.33, p.227-261, 1980.

JACKSON, J.; ASH, A.J. Tree-grass relationships in open eucalypt woodlands of Northeastern Australia: influence of trees on pasture productivity, forage quality and species distribution. Agroforestry Systems, v.40, p.159-176, 1998.

LEME, T.M.S.P.; PIRES, M. de F.A.; VERNEQUE, R. da S.V.; ALVIM, M.J.; AROEIRA, L.J.M. Comportamento de vacas mestiças Holandês x Zebu, em pastagem de Brachiaria decumbens em sistema silvipastoril. Ciência e Agrotecnologia, v.29, p.668-675, 2005.

MACEDO, M.C.M. Pastagens no ecossistema Cerrados: evolução das pesquisas para o desenvolvimento sustentável. In: REUNIÃO ANUAL DA SOCIEDADE BRASILEIRA DE ZOOTECNIA, 42., 2005, Goiânia. Anais. Goiânia: SBZ/UFG, 2005. p.56-84.

PACIULLO, D.S.C.; GOMIDE, J.A.; QUEIROZ, D.S.; SILVA, E.A.M. da. Composição química e digestibilidade in vitro de lâminas foliares e colmos de gramíneas forrageiras, em função do nível de inserção no perfilho, da idade e da estação de crescimento. Revista Brasileira de Zootecnia, v.30, p.964-974, 2001. Suplemento 1.

QUEIROZ, D.S.; GOMIDE, J.A.; MARIA, J. Avaliação da folha e do colmo de topo e base de perfilhos de três gramíneas forrageiras. 1. Digestibilidade in vitro e composição química. Revista Brasileira de Zootecnia, v.29, p.53-60, 2000.
SÁNCHEZ, S.; HERNÁNDEZ, M.; SIMÓN, L. Efecto del sistema silvopastoril en la fertilidad edáfica en unidades lecheras de la empresa Nazareno. Pastos y Forrajes, v.26, p.131-136, 2003.

SENANAYAKE, S.G.J.N. The effects of different light levels on the nutritive quality of four natural tropical grasses. Tropical Grasslands, v.29, p.111-114, 1995.

SHELTON, H.M.; HUMPHREYS, L.R.; BATELLO, C. Pastures in the plantations of Asia and the Pacific: performance and prospect. Tropical Grasslands, v.21, p.159-168, 1987.

SILVA, J.S.; QUEIROZ, A.C. da. Análise de alimentos: métodos químicos e biológicos. 3.ed. Viçosa: UFV, 2002. 235p.

WILSON, J.R. Influence of planting four tree species on the yield and soil water status of green panic pasture in subhumid south-east Queensland. Tropical Grasslands, v.32, p.209-220, 1998.

WILSON, J.R. Shade-stimulated growth and nitrogen uptake by pasture grasses in a subtropical environment. Australian Journal of Agricultural Research, v.47, p.1075-1093, 1996.

XAVIER, D.F.; CARVALHO, M.M.; ALVIM, M.J.; BOTREL, M.A. Melhoramento da fertilidade do solo em pastagem de Brachiaria decumbens associada com leguminosas arbóreas. Pasturas Tropicales, v.25, p.23-26, 2003.

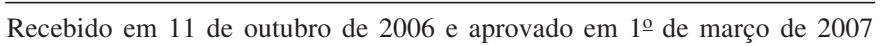

